\title{
Welding of Aluminum Alloys
}

\author{
R.R. Ambriz and V. Mayagoitia \\ Instituto Politécnico Nacional CIITEC-IPN, \\ Cerrada de Cecati S/N Col. Sta. Catarina C.P. 02250, Azcapotzalco, DF, \\ México
}

\section{Introduction}

Welding processes are essential for the manufacture of a wide variety of products, such as: frames, pressure vessels, automotive components and any product which have to be produced by welding. However, welding operations are generally expensive, require a considerable investment of time and they have to establish the appropriate welding conditions, in order to obtain an appropriate performance of the welded joint. There are a lot of welding processes, which are employed as a function of the material, the geometric characteristics of the materials, the grade of sanity desired and the application type (manual, semi-automatic or automatic). The following describes some of the most widely used welding process for aluminum alloys.

\subsection{Shielded metal arc welding (SMAW)}

This is a welding process that melts and joins metals by means of heat. The heat is produced by an electric arc generated by the electrode and the materials. The stability of the arc is obtained by means of a distance between the electrode and the material, named stick welding. Figure 1 shows a schematic representation of the process. The electrode-holder is connected to one terminal of the power source by a welding cable. A second cable is connected to the other terminal, as is presented in Figure 1a. Depending on the connection, is possible to obtain a direct polarity (Direct Current Electrode Negative, DCEN) or reverse polarity (Direct Current Electrode Positive, DCEP). The core wire of the coated electrode conducts the electric current and it provides filler metal to perform the weld.

The heat of the arc melts the wire core and the coating (flux) at the tip of the electrode. The melt material is transferring to the base metal in a drop shape, as is showed in Figure $1 \mathrm{~b}$. The molten metal is stored in a weld pool and it solidifies in the base metal. The flux due to its low density floats to the surface of the weld pool and solidifies as a layer of slag in the surface of the weld metal.

The electrode covering contents some chemical compounds, which are intended to protect, deoxidize, stabilize the arc and add alloy elements. There are basically four types of electrode coating types: (i) Cellulosic (20-60\% rutile, $10-20 \%$ cellulose, $15-30 \%$ quartz, $0-15 \%$ carbonates, $5-10 \%$ ferromanganese), which promotes gas shielding protection in the arc region, a deep penetration and fast cooling weld. (ii) Rutile ( $40-60 \%$ rutile, $15-20 \%$ quartz, 0 $15 \%$ carbonates, $10-14 \%$ ferromanganese, $0-5 \%$ organics), this is employed to form slags mainly for slag shielding, it presents high inclusion content in weld deposit. (iii) Acid (iron 
ore-manganese ore, quartz, complex silicates, carbonates ferromanganese), which provides fairly high hydrogen content and high slag content in the weld. (iv) Basic (20-50\% calcium carbonate, $20-40 \%$ fluorspar, $0-5 \%$ quartz, $0-10 \%$ rutile, $5-10 \%$ ferro-alloys), this coating brings low high hydrogen levels $(\leq 10 \mathrm{ppm})$ and electrodes can be kept dry (Easterling, 1992). Because the temperature is high, the covering of the electrode produces a shielding gas for the molten metal. During the welding process, the covering of the electrode reacts to eliminate the oxides produced in the fusion process and it cleans the weld metal. Also, the slag formed in the solidification process protects the weld metal, especially when the temperature is too high. The electric arc is produced by the ionization of the gases (plasma), which conduct the electric current. Arc stabilizers are compounds that decompose into ions arc in the form of oxalates of potassium and lithium carbonate. They increase the electrical conductivity and improve to conduct the current in softer form. Additionally, the electrode covering also provides alloying elements and/or metallic powders to the weld metal. Alloying elements tend to control the chemical composition of the weld metal; metallic powders tend to increase the deposit rate.

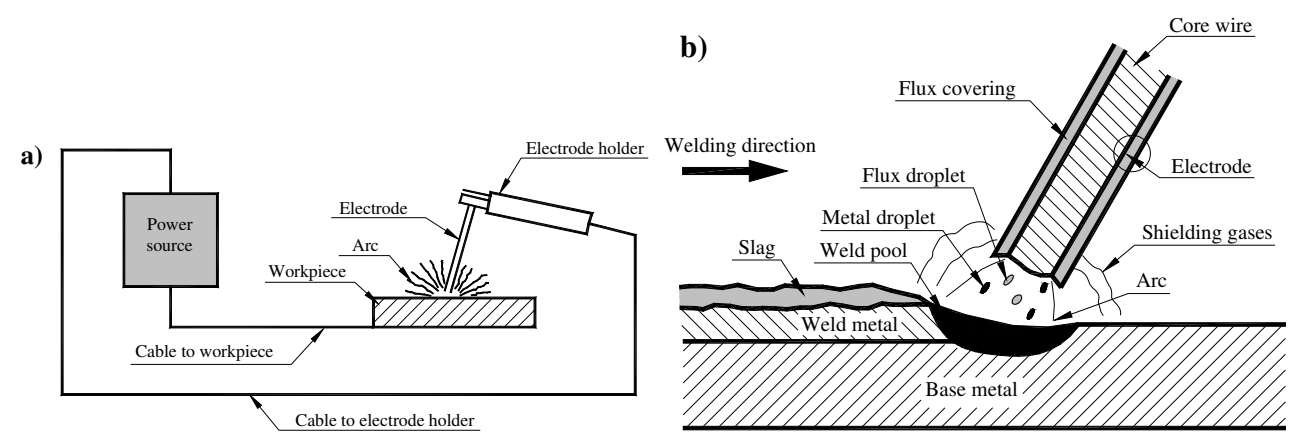

Fig. 1. Shielded metal arc welding process

Some advantages of the SMAW welding process is that it is portable and not expensive compared with others. These features allow that the SMAW process can be employed in maintenance, repair operations, production of structures or pressure vessels. However, in welding of aluminum alloys and titanium, the welding process does not provides a sufficient degree of cleaning because the gas produced by the coating is not enough to obtained welds free of defects and discontinuities. On the other hand, the deposit rate is limited because the electrodes must be changed continuously due to its length and the operator must be stop.

\subsection{Gas metal arc welding (GMAW)}

GMAW is a welding process that melts and joins metals by heating employing an electric arc established between a continuous wire (electrode) and metals to be welded, as is shown in Figure 2. Shielding protection of the arc and molten metal is carried out by means of a gas, which can be active or inert. In the case of aluminum alloys, non ferrous alloys and stainless steel Ar gas or mixtures of Ar and He are employed, whereas for steels the base of the shielding gases is $\mathrm{CO}_{2}$. When using an inert gas, it is kwon as MIG process (Metal Inert Gas) and MAG when Metal Active Gas is used. GMAW process is one of the most employed to weld aluminum alloys. 

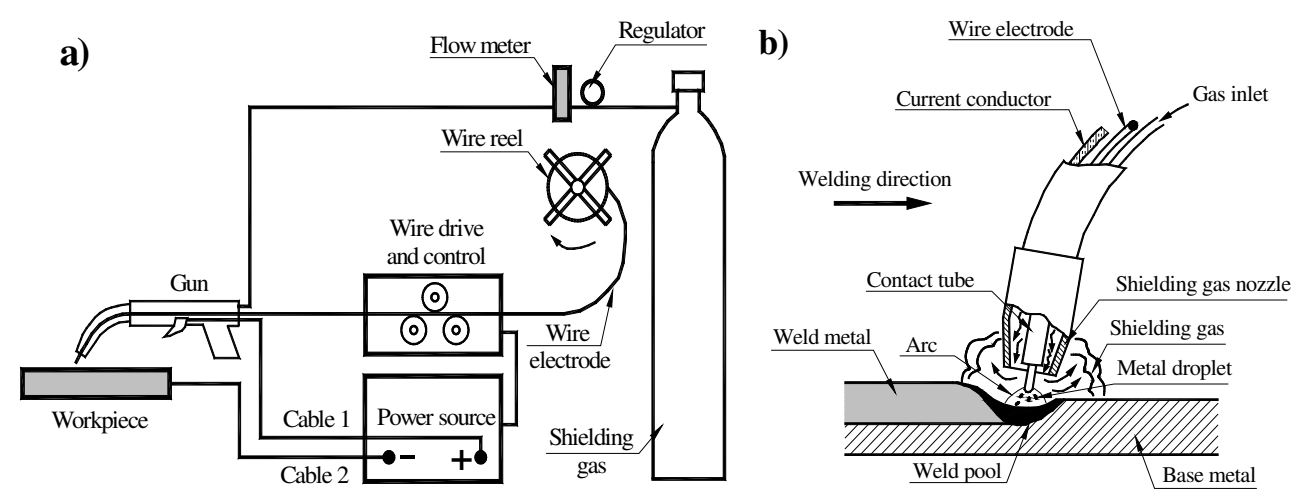

Fig. 2. Gas metal arc welding process

When using an Ar gas arc, the arc energy has a smaller spread than an arc of He, due to the low thermal conductivity of Ar. This aspect helps to obtain a metal transfer more stable and an axial Ar plasma arc. The shielding gas effect on aluminum welding is presented schematically in Figure 3. The penetration pattern is similar to a bottle nipple when using $\mathrm{Ar}$, whereas when using $\mathrm{He}$, the cross-sectional area has a parabolic penetration.
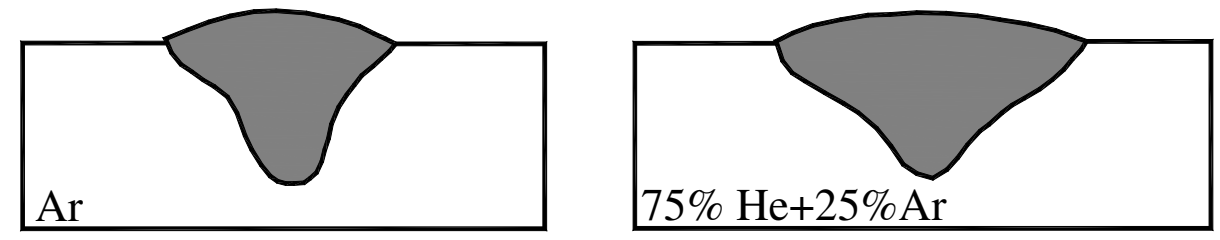

Fig. 3. Schematic representation in aluminum welds using different shielding gases

There are three basics metal transfer in GMAW process: globular transfer, spray transfer and short-circuiting transfer (Kou, 2003).

In the globular transfer, metal drops are larger than the diameter of the electrode, they travel through the plasma gas and are highly influenced by the gravity force. One characteristic of the globular transfer is that this tends to present, spatter and an erratic arc. This type of metal transfer is present at low level currents, independently of the shielding gas. However, when using $\mathrm{CO}_{2}$ and $\mathrm{He}$, globular transfer can be obtained at all current levels.

On the other hand, spray transfer occurs at higher current levels, the metal droplets travel through the arc under the influence of an electromagnetic force at a higher frequency than in the globular transfer mode. In this transfer mode, the metal is fed in stable manner and the spatter tends to be eliminated. The critical current level depends of the material, the diameter of the electrode and the type of shielding gas.

In short-circuiting transfer, the molten metal at the electrode tip is transferred from the electrode to the weld pool when it touches the pool surface, that is, when short-circuiting occurs. The short-circuiting is associated with lower levels of current and small electrode diameters. This transfer mode produces a small and fast-freezing weld pool that is desirable for welding thin sections, out-of-position welding and bridging large root openings. Figure 4 , shows the typical range of current for some wire diameters. 


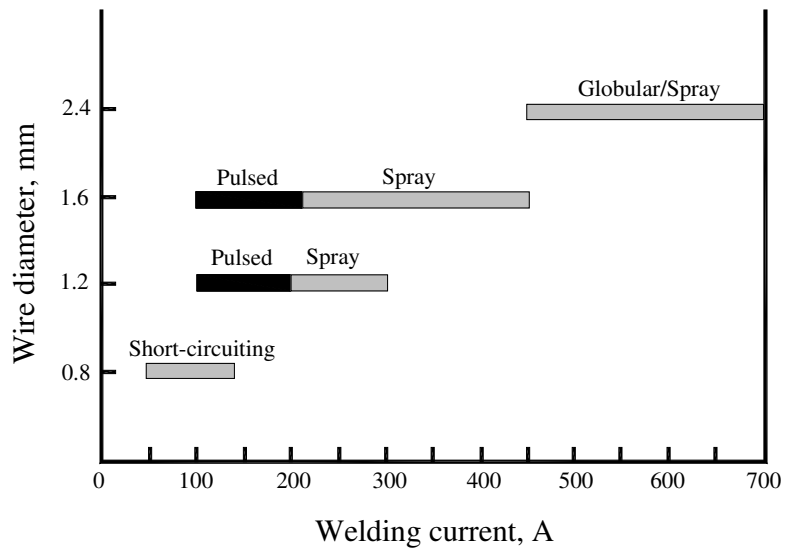

Fig. 4. Typical welding current ranges for wire diameter and welding current

The principal advantages of GMAW process with respect to SMAW process are: (i) There is not production of slag. (ii) Is possible to perform welds in all welding positions. (iii) Rate deposition is roughly two times than SMAW. (iv) Quality of the welds is very good. (v) Is possible to weld materials with a short-circuiting transfer mode, which tends to improve the reparation and maintenance operations.

\subsection{Gas tungsten arc welding (GTAW)}

This is a welding process that melts metal by heat employing an electric arc with a non consumable electrode. GTAW process employs an inert or active shielding gas, which protects the electrode and the weld metal. A schematic representation of GTAW process is showed in Figure 5. The arc functions as a heat source, which can be directly used for welding, with or without the use of filler materials. This process produces high quality welds, but the principal disadvantage is that the rate of deposition is slow and it limits the range of application in terms of thickness. For instance, in welding of aluminum alloys it is convenient to use this welding process in thickness no greater than $6 \mathrm{~mm}$, since greater thicknesses require a large number of passes and the welding operation tends to be expansive and slow.

a)

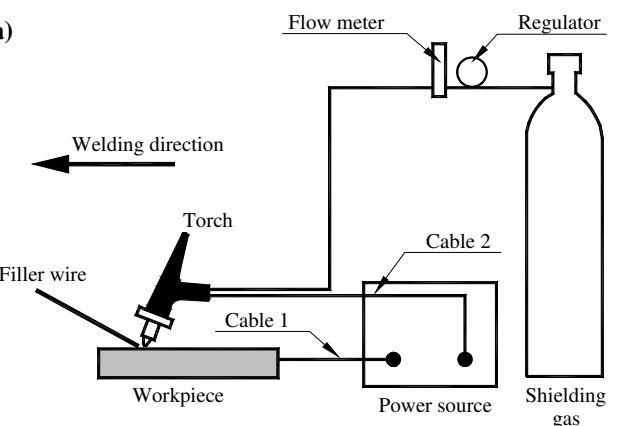

b)

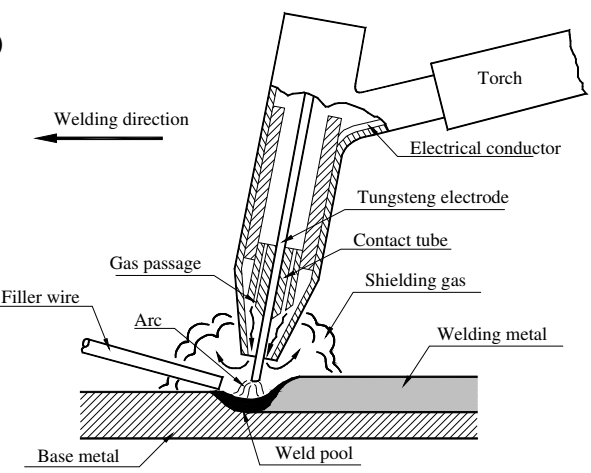

Fig. 5. Schematic representation of GTAW process 
It is possible to use Direct Current (DC) or Alternating Current (AC) to weld by GTAW. In the case of DC, we can use direct polarity (electrode negative, DCEN) or reverse polarity (positive electrode, DCEP), Figure 6, shows the polarity effect on the weld.

Direct polarity is the most commonly employed in GTAW. In this case, the electrode is connected to the negative pole of the heat source and the electrons are emitted from the electrode and they are accelerated as they travel through the arc (plasma). This effect produces a high heat in the workpiece and therefore gives a good penetration and a relatively narrow weld shape.

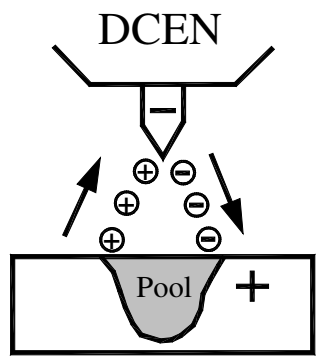

Deep weld

no surface cleaning

(a)

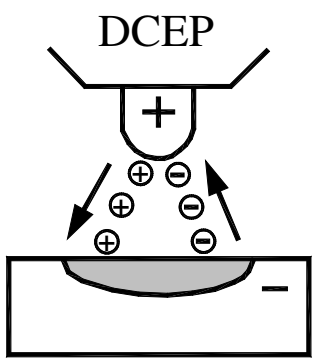

Shallow weld surface cleaning

(b)

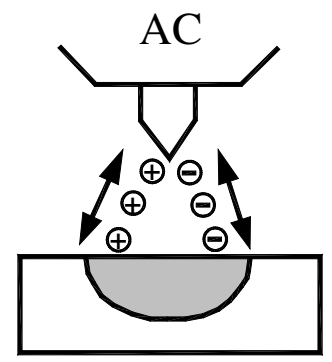

Intermediate

(c)

Fig. 6. Polarity in GTAW

On the other hand, when reverse polarity is used, the electrode is connected to the positive pole of the heat source. Now the effect of the heating due to the bombardment of the electrons is higher in the electrode than that of workpiece, which results in a wide weld bead and shallower than that generated by direct polarity. In this case, due to high energy concentration in the electrode it is necessary to employ a thicker diameter and a cooling system to eliminate the electrode tip melting possibility. The bombardment effect by positive ions of the inert gas removes the oxide film and produces a cleaning effect on the welding surface. Therefore, reverse polarity can be used to weld materials that are resistant to oxides such as aluminum and magnesium, if it is not required a high penetration.

When alternating current is used, is possible to obtain a good combination of oxides elimination (cleanliness) and penetration, as is presented in Figure 6. This polarity is the most employed to weld aluminum alloys.

There are several types of electrodes to weld by GTAW. These include pure tungsten and tungsten alloyed with thorium oxide $\left(\mathrm{ThO}_{2}\right)$ or zirconium oxide $\left(\mathrm{ZrO}_{2}\right)$, which are added to improve the arc ignition and to increase the life of electrode. In the last years some alloy elements have been incorporated, such as cerium and lanthanum, which also increase the life of the electrode and tend to decrease the risk of radiation that is produced when electrodes of high thorium content are employed. Zirconium electrodes are preferred for $\mathrm{AC}$, because they present a higher melting point than pure tungsten or tungsten-thorium.

During the welding process, it is assumed that the electrode tip is hemispherical type. This is a very important aspect, because the arc stability depends in a greater manner of tip geometry. There are electrodes of varies diameters, which can range from 0.3 to $6.4 \mathrm{~mm}$. Table 1 presents the recommended current ratings for different diameters of electrodes using Ar shielding gas. 


\begin{tabular}{cc}
\hline Electrode diameter, $\mathrm{mm}$ & Current, $\mathrm{A}$ \\
\hline 1.0 & $20-50$ \\
1.6 & $50-80$ \\
2.4 & $80-160$ \\
3.2 & $160-225$ \\
4.0 & $225-330$ \\
5.0 & $330-400$ \\
6.4 & $400-550$ \\
\hline
\end{tabular}

Table 1. Recommended electrode diameters and current range employed with Ar shielding gas

Table 2, presents the gases used as a protection, in GMAW and GTAW. A shielding gas is selected according to their ionization potential, density, degree of protection and the effect of oxides removal. For example, it is easier to ionize an Ar gas $(15.7 \mathrm{eV})$ than a He gas $(24.5 \mathrm{eV})$, and due to this effect the arc ignition tends to be more easy. Furthermore, the Ar density is higher than He and consequently the penetration of the weld bead is better.

\begin{tabular}{ccccc}
\hline Gas & $\begin{array}{c}\text { Chemical } \\
\text { symbol }\end{array}$ & $\begin{array}{c}\text { Molecular } \\
\text { weigth, g/mol }\end{array}$ & Density, g/L & $\begin{array}{c}\text { Ionization } \\
\text { potential, eV }\end{array}$ \\
\hline Argon & $\mathrm{Ar}$ & 39.95 & 1.784 & 15.7 \\
Carbon dioxide & $\mathrm{CO}_{2}$ & 44.01 & 1.978 & 14.4 \\
Helium & $\mathrm{He}$ & 4.00 & 0.178 & 24.5 \\
Hydrogen & $\mathrm{H}_{2}$ & 2.016 & 0.090 & 13.5 \\
Nitrogen & $\mathrm{N}_{2}$ & 28.01 & 1.25 & 14.5 \\
Oxygen & $\mathrm{O}_{2}$ & 32.00 & 1.43 & 13.2 \\
\hline
\end{tabular}

Table 2. Gas shielding properties employed in GMAW and GTAW (Kou, 2003)

\subsection{Friction stir welding (FSW)}

Friction-Stir Welding (FSW) is a solid-state, hot-shear joining process (Thomas et al.; 1991, Thomas \& Dolby, 2003, Dawes \& Thomas, 1996, Mishra \& Ma, 2005). The process utilizes a bar-like tool in a wear-resistant material (generally tool steel for aluminum) with a shoulder and terminating in a threaded pin. This tool moves along the butting surfaces of two rigidly clamped plates placed on a backing plate. The shoulder makes a contact with the top surface of the plates to be welded. The heat generated by friction at the shoulder and to a lesser extent at the pin surface and it softens the material being welded. Severe plastic deformation and flow of this plasticised metal occurs as the tool is translated along the welding direction. The material is transported from the front of the tool to the trailing edge where it is forged into a joint. Figure 7 shows a schematic representation of FSW.

There are two principal parameters in FSW: tool rotation rate $(\omega, \mathrm{rpm})$ in clockwise or counterclockwise direction and the tool traverse speed $(v, \mathrm{~mm} / \mathrm{min})$ along the line of joint. The rotation of the tool results in stirring and mixing of material around the rotating pin and the translation of the tool moves the stirred material from the front to the back of the pin and finishes welding process. Additionally, the angle of spindle or tool tilt and pressure are other important process parameters. A suitable tilt of the spindle towards trailing direction ensures that the shoulder of the tool holds the stirred material by threaded pin and move material efficiently from the front to the back of the pin. The heat generation rate, 

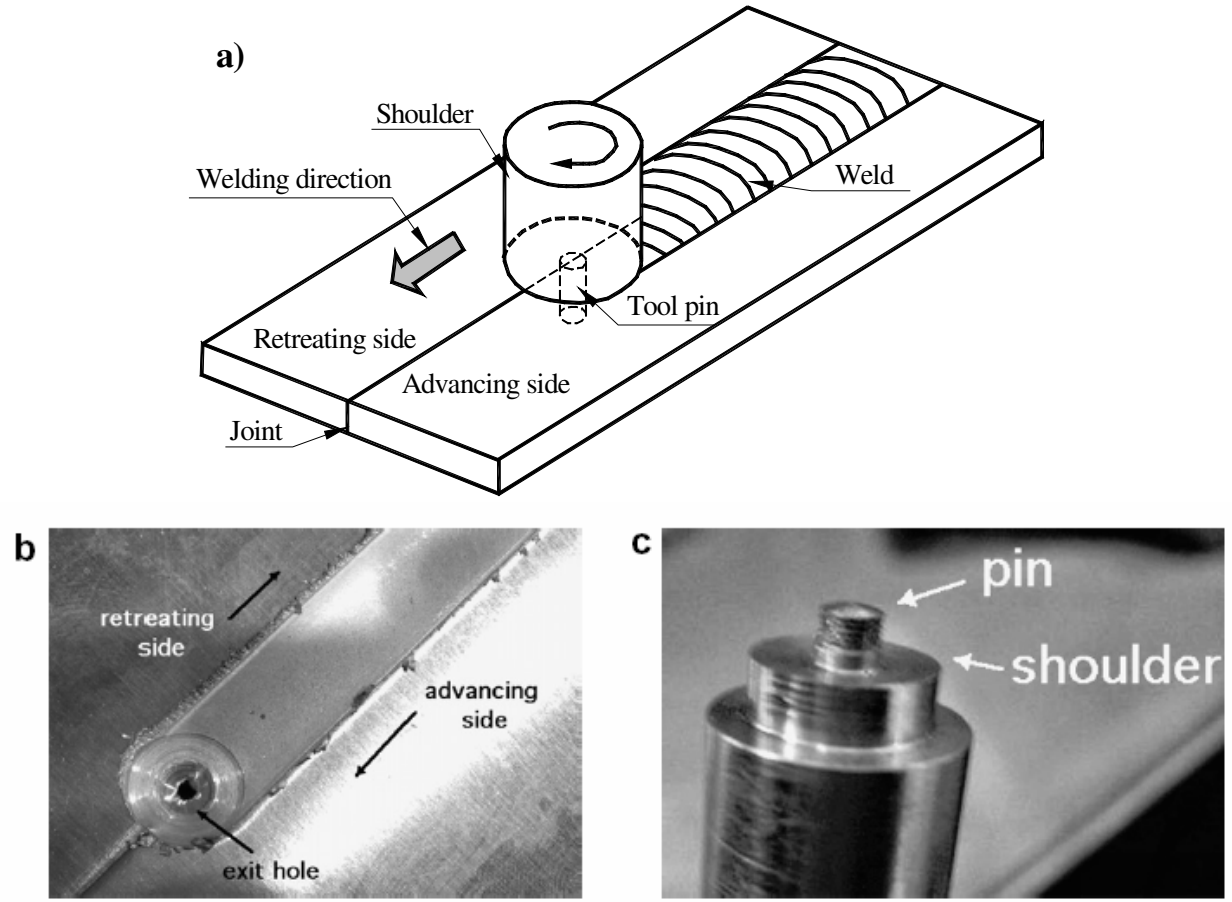

Fig. 7. Illustration of the friction-stir welding process, b) weld between aluminum sheets and c) An actual tool with a threaded-pin

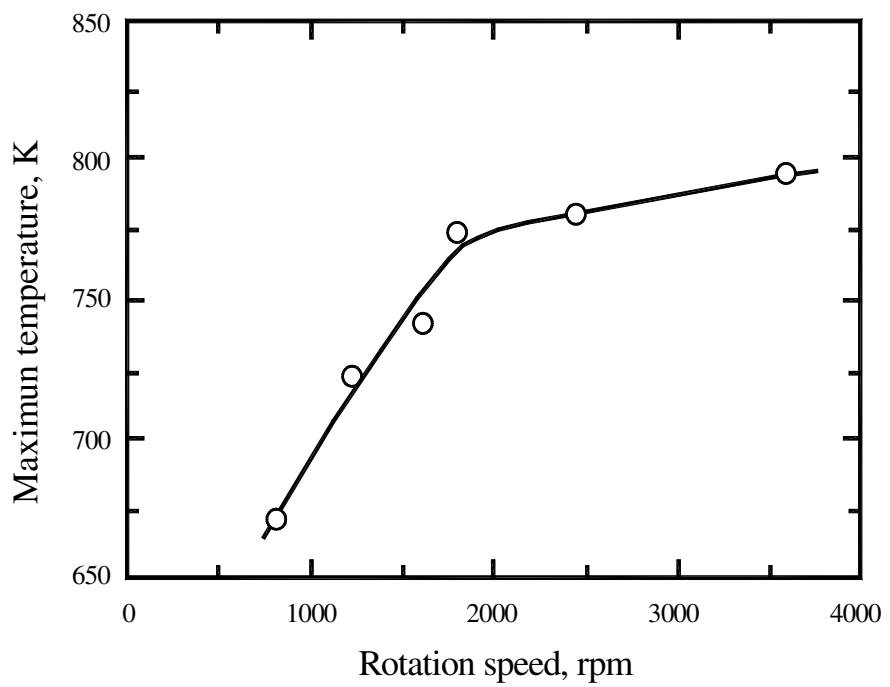

Fig. 8. Relationship between rotational speed and peak temperature in FSW of AA6063 (Sato et al., 2002) 
temperature field, cooling rate, $x$-direction force, torque and power are totally depended of the welding speed, the tool rotation speed, the vertical pressure on the tool, etc. Figure 8 , shows a relationship between rotational speed and peak temperature in FSW of a 6063 aluminum alloy (Nandan et al., 2008).

FSW enables long lengths of weld to be made without any melting taking place. This provides some important metallurgical advantages compared with fusion welding, i.e. no melting means that solidification and liquation cracking are eliminated; dissimilar alloys can be successfully joined; the stirring and forcing action produces a fine-grain structure. However, one disadvantage is that the keyhole (exit hole) remains when the tool is retracted at the end of the joint (Figure $7 \mathrm{~b}$ ).

Several alloys have been welded by FSW, they included the following aluminum alloys: 5083, 5454, 6061, 6082, 2014, 2219 and 7075 (Nandan et al., 2008).

\subsection{Modified indirect electric arc welding technique (MIEA)}

Although, welding of aluminum alloys is relatively easy employing friction stir welding, when the thickness is thick a fusion welding process is usually required to join these materials. In the case of a fusion welding process, a large amount of heat input can be dissipated via heat conduction throughout the base material close to the welded zone. Typically, this thermal dissipation induces localized isothermal sections where the thermal gradient can have important and detrimental effects on the microstructure and therefore on the mechanical properties of the material constituting the heat affected zone (HAZ), specially in aluminum alloys hardening by artificial ageing (Myhr et al., 2004). In order to improve the mechanical and microstructural conditions of the welded joint in aluminum alloys, the Modified Indirect Electric Arc (MIEA), has been developed (Ambriz at al., 2006, Ambriz et al. 2008). This welding technique is based on a simple joint modification which provided several advantages with respect to the traditional arc fusion welding process, for instance:

i. The high thermal efficiency that allows welding plates by using a single welding pass. As a result, the thermal effect is reduced and the mechanical properties of the HAZ are improved as compared to a multi-pass welding procedure,

ii. The dilution percent of the weld pool is higher; which tends to improve the hardening effect after performing a post weld heat treatment (PWHT) (Ambriz et al., 2008),

iii. The solidification mode promotes an heterogeneous nucleation and jointly diminishes the micro-porosity formation,

iv. The geometry of the welding profile improves the fatigue performance of the welded joint (Ambriz et al., 2010a).

MIEA welding technique employs the same equipment that is required to weld by GMAW. A schematic representation of the MIEA joint is present in Figure 9.

\section{Importance of microstructure and mechanical properties on aluminum welds}

After welding, the microstructure and mechanical properties conditions are the principal aspects that determine the appropriate perform in structures and components of aluminum alloys. It means that it is necessary to know exactly the mechanical behavior of the welded joint, including the global and local mechanical properties. This is necessary because the temperature susceptibility of some aluminum alloys tends to change in a great manner the microstructure conditions in the fusion zone and in the HAZ. Here are some results on the 
microstructural and mechanical conditions in welding of aluminum alloys, especially for FSW and MIEA.
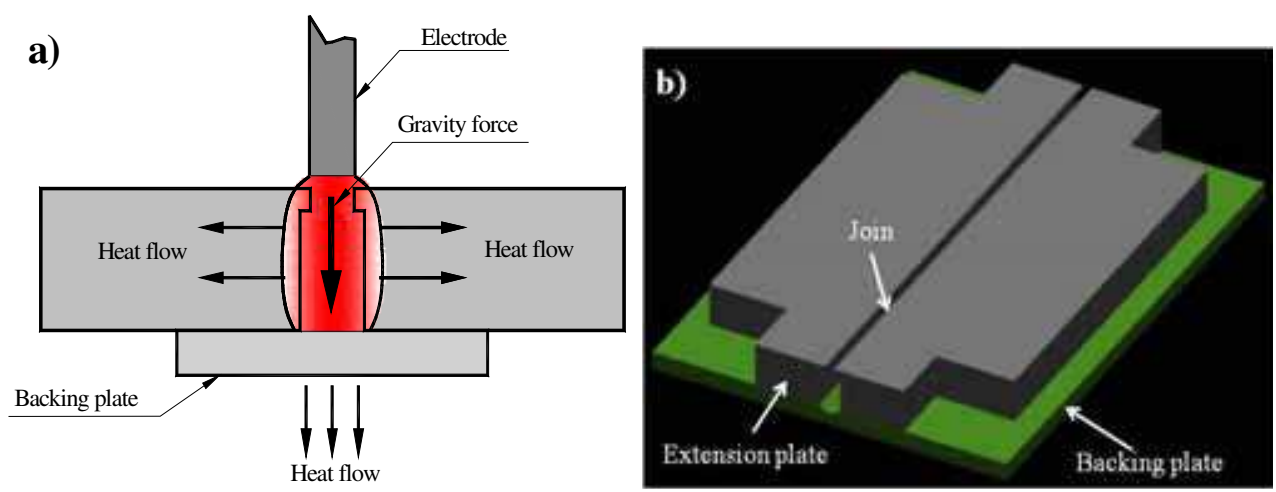

Fig. 9. Schematic representation of MIEA welding technique

\subsection{Microstructure}

After a fusion welding process two principal zones are identified in the welded joints named: Fusion Zone (FZ) and Heat Affected Zone (HAZ) whereas in the case of FSW three different zones are formed: stirred zone (nugget), Thermo-Mechanical Affected Zone (TMAZ) and the HAZ (Mishra \& Ma, 2005). These zones are showed in the macrographs of Figure 10 .
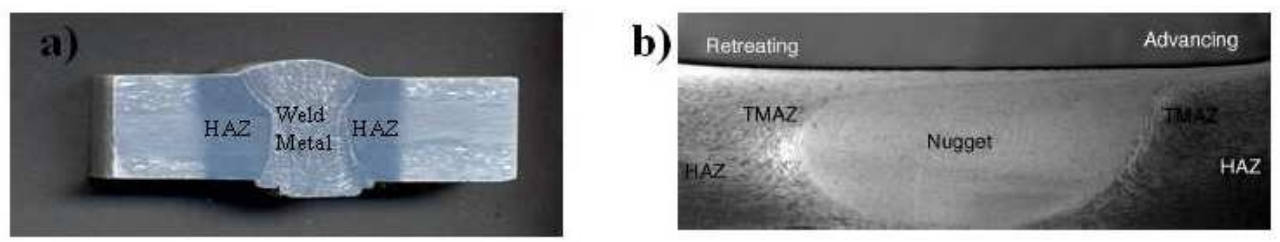

Fig. 10. Principal zones in welding of aluminum, a) MIEA welding technique (Al-6061-T6) and b) FSW (Al-7075-T651)

\subsubsection{Weld metal microstructure in MIEA}

In a fusion welding process, the heat input produces a fusion-solidification phenomenon, which is different to that obtained in the solidification of an ingot. (i) In an ingot, solidification begins with heterogeneous nucleation at the chill zone meanwhile in a weld pool the liquid metal partially wets the grains of the parent metal and epitaxial growth takes place from the partially melted grains of the parent metal (Davies et al., 1975). (ii) The rate of solidification in a weld pool, which depends on the traveling speed as well as the welding process, is by far faster than in an ingot. (iii) The macroscopic profile of the solid/liquid interface in welds progressively changes as a function of the traveling speed of the heat source whereas it exclusively depends on the time for an ingot. (iv) The movement of the liquid metal in a weld pool is greater than in an ingot due to the Lorentz forces which create turbulence within the molten metal (Grong, 1997). Figure 11 shows longitudinal views, 
which depict the direction of solidification of the welds, for a multi-pass welding and MIEA with different preheating conditions. The arrows indicate the displacing direction of the electric arc.
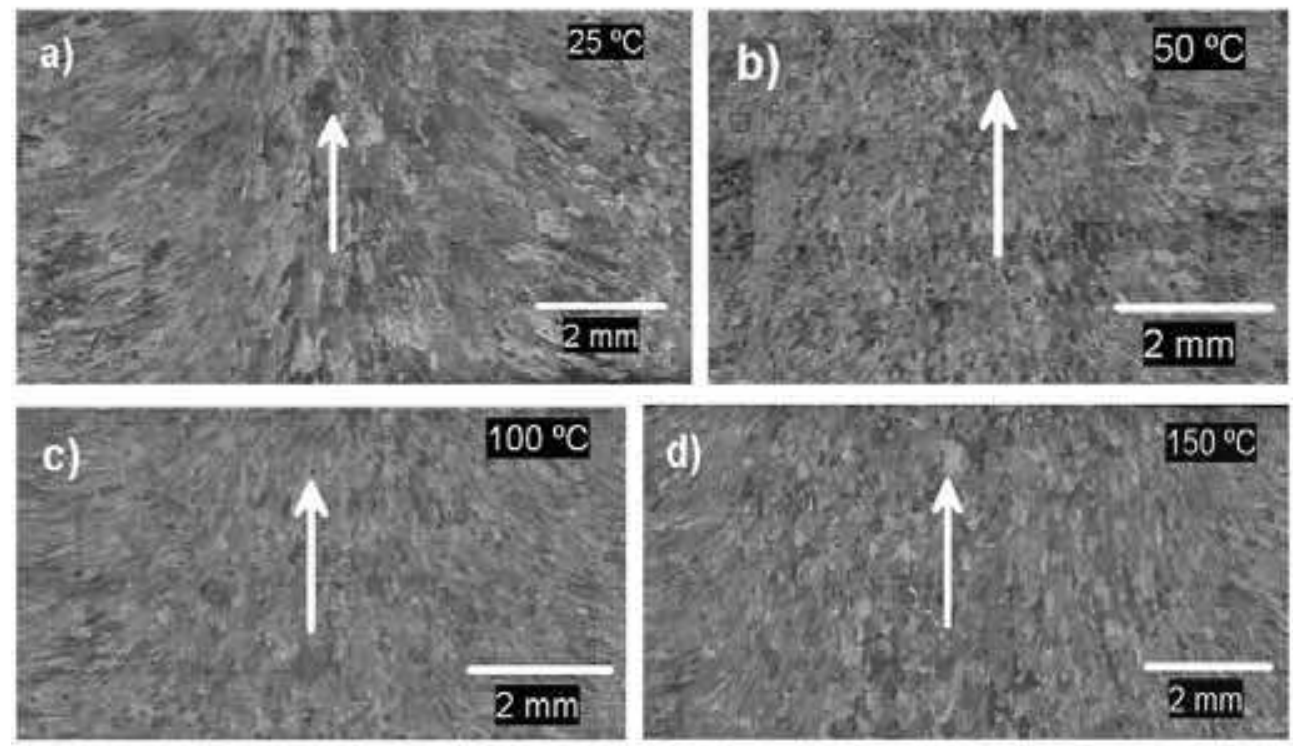

Fig. 11. Longitudinal top view of the weld metal grain structure at the mid plane for:

a) single $V$ groove, $b$ )-d) MIEA

Figure 11a corresponds to the single $\mathrm{V}$ groove joint and it shows the crystalline growth of a columnar-dendritic structure at a given angle with respect to the direction of the heat source. This feature is determined by the traveling speed of the welding torch. In this instance, the rate of the local crystalline growth tends to be that of the welding process. This phenomenon is illustrated by means of a schematic representation in Figure 12.

It is possible to observe that the local crystalline growth, $R_{L}$, is always larger than the nominal crystalline growth, $R_{N}$, since there are directions in which growth occurs preferentially. Thus, the rate of crystalline growth tends to be the traveling speed of the heat source, $v$, when the angles are less pronounced (when $\alpha \rightarrow 0$ and $\phi \rightarrow 0$ ), according to the following equation (Grong, 1997).

$$
R_{L}=\frac{R_{N}}{\cos \phi}=\frac{v \cos \alpha}{\cos \phi}
$$

The changes in direction are readily appreciated for the longitudinal view shown in Figure 11a. Competitive growth toward the heat source is evident, giving rise to columnar grains; this characteristic is typical of arc fusion welding processes. Analyzing equation (1) along with Figure 12, it is apparent the increase of the rate of crystalline growth as a function of the changes in orientation of the crystalline growth with regard to the largest thermal gradient of the weld pool. It is clear thus that local crystalline growth is favored due to the prevailing high temperature conditions. 


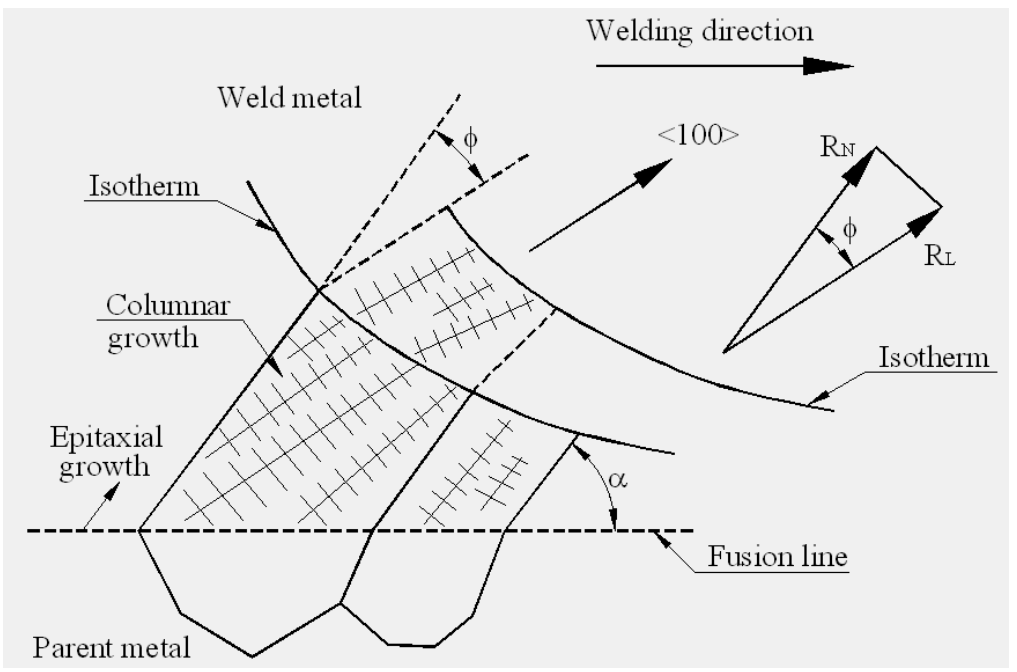

Fig. 12. Schematic representation of the local and nominal crystal growth rate (Ambriz et al., 2010b)

The longitudinal macrostructures for the MIEA joint, Figures 11b-d, exhibit significant differences with respect to the multi-passes single $\mathrm{V}$ groove joint. Irrespective of the preheating condition, the local crystalline growth maintains an angle nearly constant in relation to the moving heat source. The virtual non existence of changes in growth direction means that the local and nominal rates of crystalline growth tend to be equal. This phenomenon yields a significantly different grain structure in the weld metal for the MIEA joint as compared to the structure observed for the single $V$ groove joint. It leads, in fact, to a grain refining effect which is obviously affected by the initial preheating temperature of the joint.

Figure 13 shows the grain structure at the bottom, mid height and top of the welds. These micrographs correspond to equivalent positions between welds and were captured at the same magnification. A dramatic change in the size and morphology of the grains is observed for the single $\mathrm{V}$ groove joint. Besides, some levels of porosity, as indicated by the arrows, are visible. The fine grain size present in the root pass is ascribed to the rapid cooling and/or to recrystallisation effects owing to subsequent welding passes which increased the heat input and caused grain growth toward the top of the weld. Microstructural examination of the fusion line revealed epitaxial growth from partially melted grains and columnar-dendritic grains. The micrograph in Figure 13 at the top of the single $\mathrm{V}$ weld shows that this solidification mechanism prevails between welding passes. On the other hand, the microstructures obtained for the MIEA joints do not exhibit major changes in morphology and size with regard to position. Thus, while the microstructures for the single $\mathrm{V}$ groove joint show that competitive growth occurs during solidification, the MIEA joint exhibit signs of heterogeneous nucleation which promotes grain refining. Figure 14 shows a micrograph obtained in the Scanning Electron Microscope showing heterogeneous nucleation in MIEA. Also, the levels of porosity in the MIEA joints decrease with preheating temperature $\left(50,100\right.$ and $150{ }^{\circ} \mathrm{C}$ ) and are comparatively lower than that obtained in the single $\mathrm{V}$ groove joint. Epitaxial solidification is also observed at the fusion 
line of the MIEA welds, however, competitive columnar growth was restricted instead grain structures alike those observed in the centre of the weld metal (Figure 13) were present. The characteristics of solidification observed for the MIEA welds in Figure 13 are the result of heterogeneous nucleation which is based on the principle of the formation of a critical radii needed to achieve the energy of formation from potential sites for nucleation such as inclusions, substrates or inoculants (Ti or Zr) (Rao et al., 2008; Ram et al., 2000; Lin et al., 2003). For the MIEA welds, these sites are principally the sidewalls of the joint in conjunction with the content of $\mathrm{Ti}$ in the filler and base metal since the significant dilution of base metal favors incorporation of Ti into the weld pool.

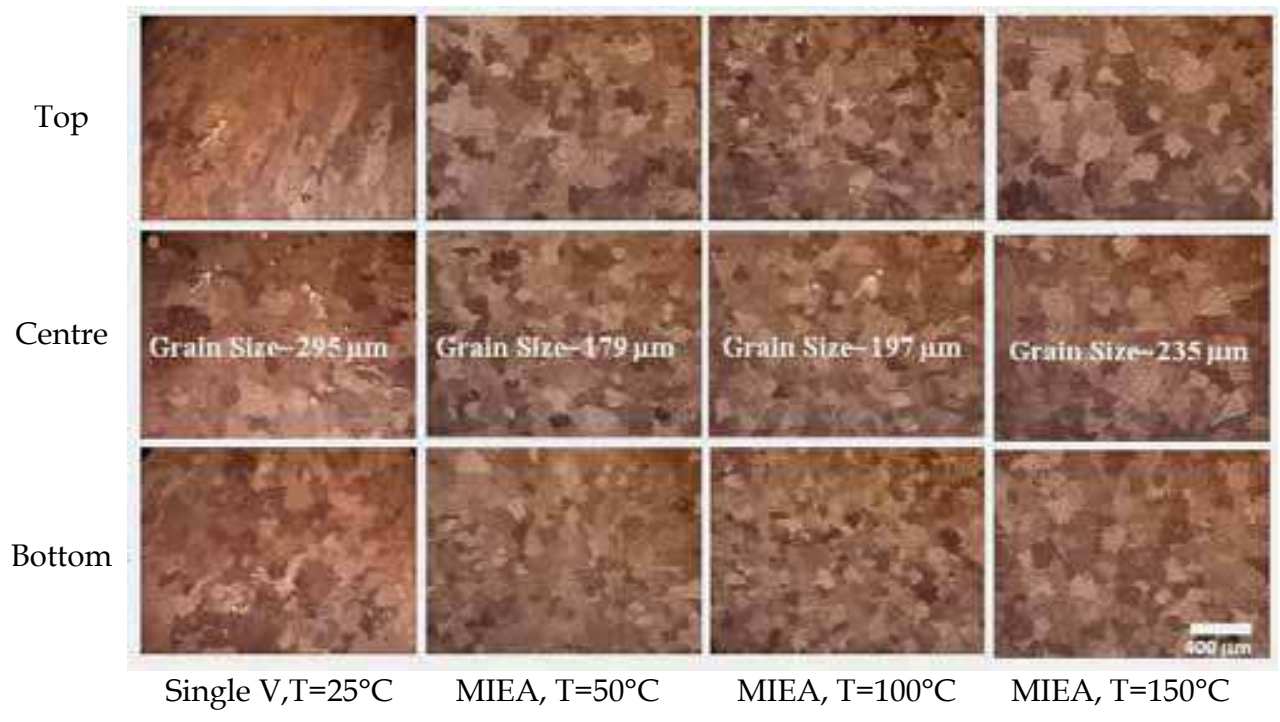

Fig. 13. Optical micrographs in welding of 6061-T6 for multipass welding process and MIEA with three different preheating $\left(50,100\right.$ and $\left.150{ }^{\circ} \mathrm{C}\right)$
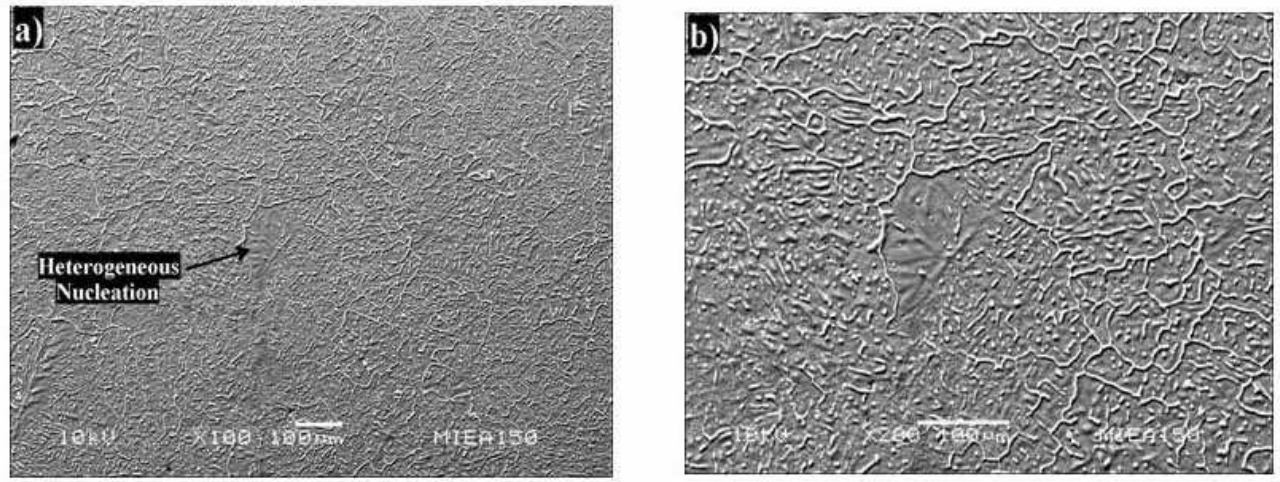

Fig. 14. Scanning electron micrographs showing heterogeneous nucleation in welding of 6061-T6 aluminum alloy obtained by MIEA 
Generally speaking MIEA joint yields homogeneous grain refined microstructures in the weld metal, having the average grain size well below than that obtained with the conventional single $\mathrm{V}$ groove joint. The differences in grain size and morphology between single- $\mathrm{V}$ groove and MIEA joints are expected to have a significant impact on the mechanical performance of the welds. Before dealing with this aspect, it is worth to elucidate about the possible mechanism that gives rise to a self-refining effect when welding with the MIEA joint technique.

\subsubsection{Nugget zone in FSW}

The intense plastic deformation and frictional heating during FSW results in the generation of a recrystallized fine-grained microstructure within the stirred zone (Mahoney et al., 1998). This is usually referred to as a weld nugget (or nugget zone) or dynamically recrystallized zone. Also, under the same FSW conditions, onion ring structure is observed in the nugget zone, as is presented in Figure 15.

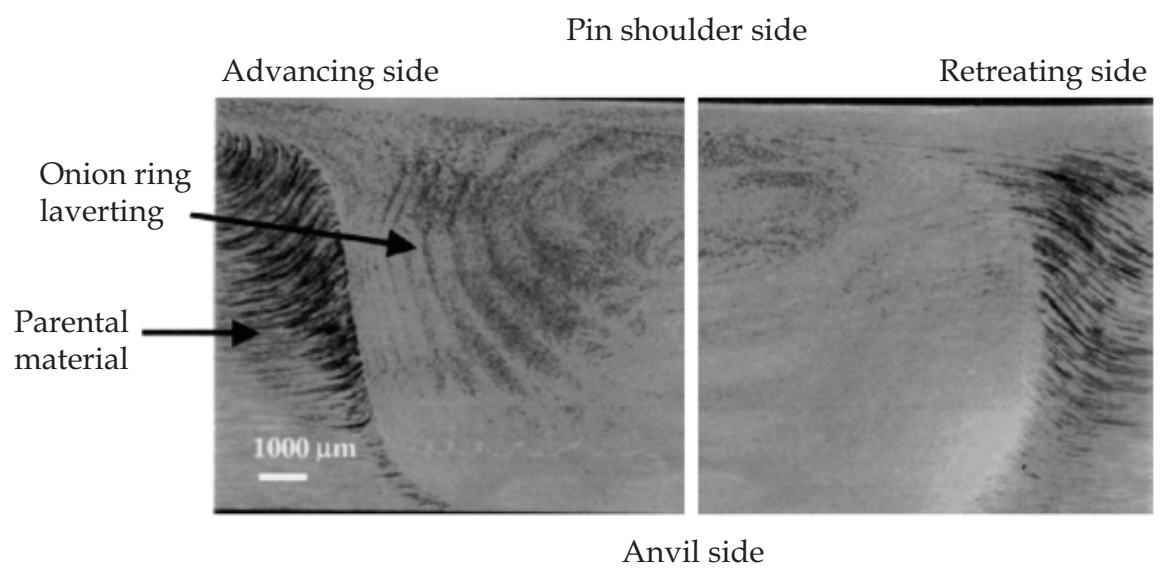

Fig. 15. Optical image showing the macroscopic features (Nandan et al., 2008) in a transverse section of FSW of 2195-T81 Al-Li-Cu alloy. Note the onion-ring and the adjacent large upward movement of material

Depending on the processing parameter, tool geometry, temperature of the workpiece, and thermal conductivity of the material, various shapes of nugget zone have been observed. Basically, nugget zone can be classified into two types, basin-shaped nugget that widens near the upper surface and elliptical nugget. Sato et al. (Sato et al., 1999) reported the formation of basin-shaped nugget on friction FSW of 6063-T5 aluminum alloy plate. They suggested that the upper surface experiences extreme deformation and frictional heating by contact with a cylindrical-tool shoulder during FSW, thereby resulting in generation of basin-shaped nugget zone. On the other hand, Rhodes et al. (Rhodes et al., 1997) and Mahoney et al. (Mahoney et al., 1998) reported elliptical nugget zone in the weld of 7075T651 aluminum alloy.

In terms of grain size it is well know that FSW produces a fine structure, which is a direct function of the welding parameters like: tool geometry, chemical composition of the workpiece, temperature of the workpiece, vertical pressure and active cooling. For example, 
in FSW of 6061-T6 aluminum alloy is possible to obtain a grain size near to $10 \mu \mathrm{m}$ (Liu et al., 1997). Figure 16 illustrates the characteristic microstructures in 2024 and 6061 aluminum alloys welds obtained by FSW. One of the principal parameters which affect the grain size in FSW is the tool rotation, as was reported previously (Sato et al., 2002).
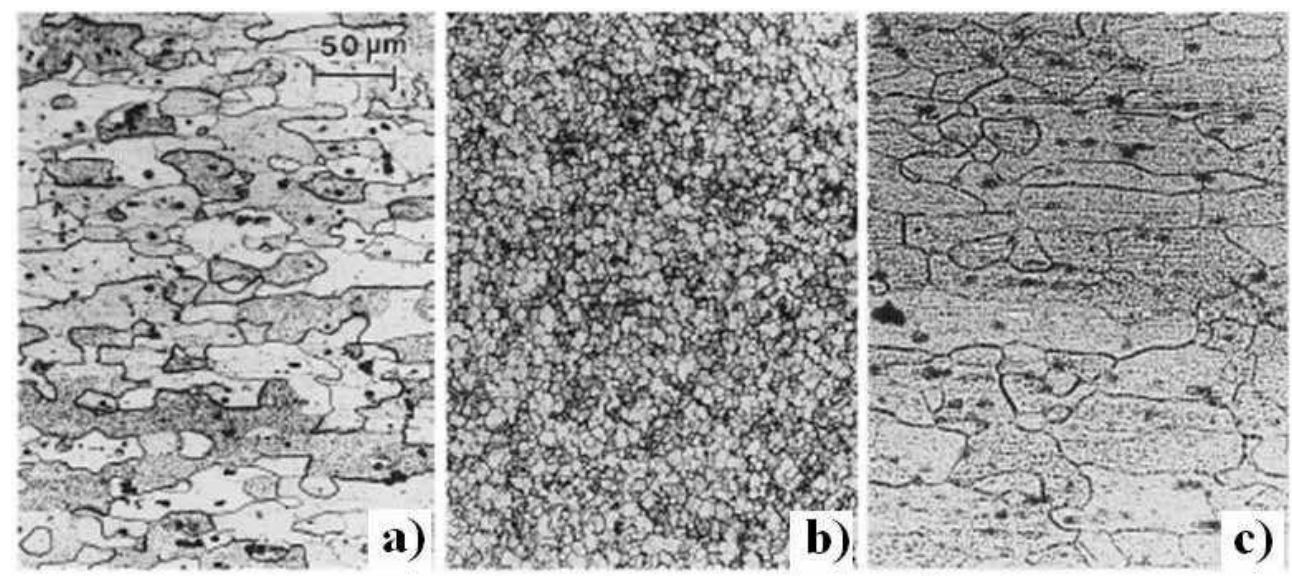

Fig. 16. Representative 2024Al/6061 Al FSW microstructure comparison, a) $2024 \mathrm{Al}$ base plate grain structure, b) $2024 \mathrm{Al}$ lamellar weld zone grain structure and c) $6061 \mathrm{Al}$ base plate grain structure (Li et al., 1999)

\subsubsection{Thermo-mechanically affected zone}

In FSW a Thermo-Mechanically Affected Zone (TMAZ) is formed between the parent metal and the nugget zone, as shown in Figure 10b. The TMAZ experiences both temperature and deformation during welding process. The TMAZ is characterized by a highly deformed structure. Although the TMAZ underwent plastic deformation, recrystallization does not occur in this zone due to insufficient deformation strain. However, dissolution of some precipitates is observed, due to the high-temperature. The extent of dissolution depends on the thermal cycle experienced by TMAZ.

\subsubsection{Heat affected zone}

Heat Affected Zone (HAZ) is present in fusion welding as well as in FSW processes. The wide of this zone is a direct function of the heat input and the thermal conductivity of the materials to be welded. Obviously the HAZ in FSW tends to be lower than that obtained in a fusion welding process. The HAZ is very important in welding of aluminum alloys, especially in alloys hardened by precipitation (artificial ageing), for instance 2024-T6, 2014T6, 6061-T6 and 7075-T6. During artificial ageing in Al-Mg-Si alloys (6000 series), a high density of fine, needle-shaped $\beta^{\prime \prime}$ particles are formed uniformly in the matrix (aluminum, $\alpha$ ). This precipitate is the dominating hardening phase, which is produced according to the following precipitation sequence (Dutta \& Allen, 1991).

$$
\begin{gathered}
\text { Super-Saturated Solid Solution (SSS) } \rightarrow \text { Solutes clustering } \rightarrow \text { GP zones (spherical) } \rightarrow \\
\qquad \beta^{\prime \prime} \text { (needle) } \rightarrow \beta^{\prime}(\text { bar }) \rightarrow \beta
\end{gathered}
$$


However, since these precipitates are thermodynamically unstable in a welding process, the smallest ones will start to dissolve in parts of the HAZ where the peak temperature has been above the ageing temperature $\left(>160^{\circ} \mathrm{C}\right)$, while the larger ones will continue grow (Dutta \& Allen, 1991). Close to the weld fusion line full reversion of the $\beta^{\prime \prime}$ particles is achieved. At the same time, coarse rod-shaped $\beta^{\prime}$ precipitates may form in the intermediate peak temperature range. This microstructural transformation is showed in Figure 17.
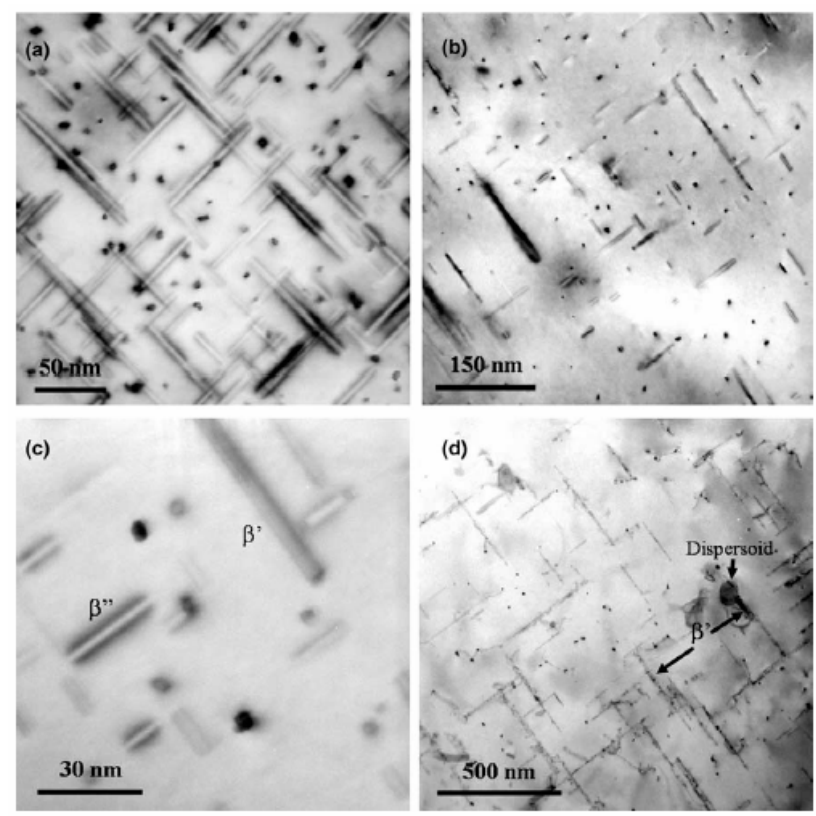

Fig. 17. TEM bright field images of microstructures observed in the «100〉 $\mathrm{Al}$ zone axis orientation after artificial ageing and Gleeble simulation (Series 1), a) Needle-shaped $\beta^{\prime \prime}$ precipitates which form after artificial ageing, b) Mixture of coarse rod-shaped $\beta^{\prime}$ particles and fine needle-shaped $\beta^{\prime \prime}$ precipitates which form after subsequent thermal cycling to $T_{\mathrm{p}}=$ $315^{\circ} \mathrm{C}$ (10 s holding time), c) Close up of the same precipitates shown in b) above, d) Coarse rod-shaped $\beta^{\prime}$ particles which form after thermal cycling to $T_{\mathrm{p}}=390^{\circ} \mathrm{C}$ (10 s holding time) (Myhr et al., 2004)

\subsection{Mechanical properties}

\subsubsection{Microhardness}

In order to determine the effect of the welding process in aluminum alloys, a common practice is to perform a microhardness profile in a perpendicular direction to the weld bead, as is showed in Figure 18. Standard Vickers measurements are conducted with an appropriate penetration force and time, i.e. $1 \mathrm{~N}$ and $15 \mathrm{~s}$. The indentation is measured and the hardness is calculated applying equation 2 :

$$
H V=1.8544 \frac{P}{d^{2}}
$$


where $H V$ is expressed in MPa if $P$ is given in $\mathrm{N}$ and $d$, the indent diagonal, in $\mathrm{mm}$.

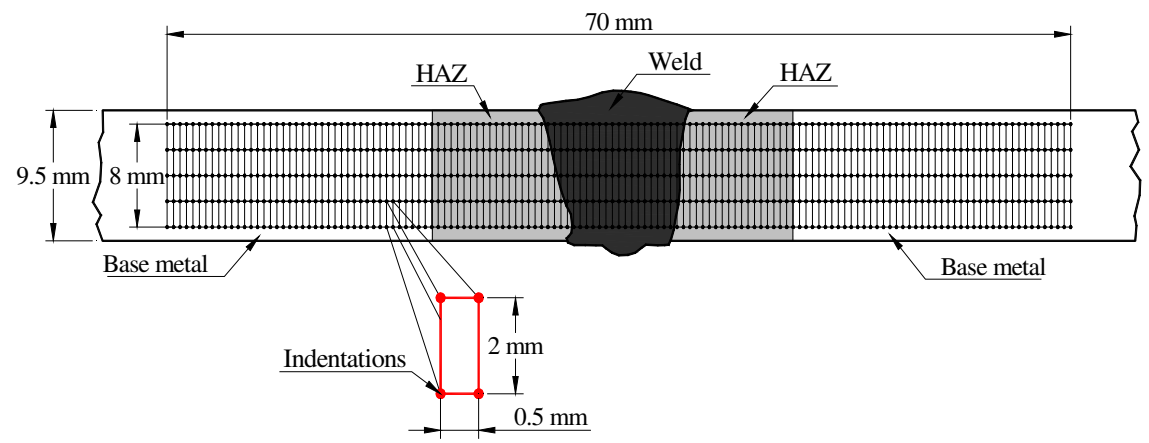

Fig. 18. Mesh definition for classical Vickers indentation measurements

Microhardness measurements give a general idea of the microstructural transformations and the variation of the local mechanical properties (Ambriz et al. 2011) produced after a welding process in aluminum alloys.

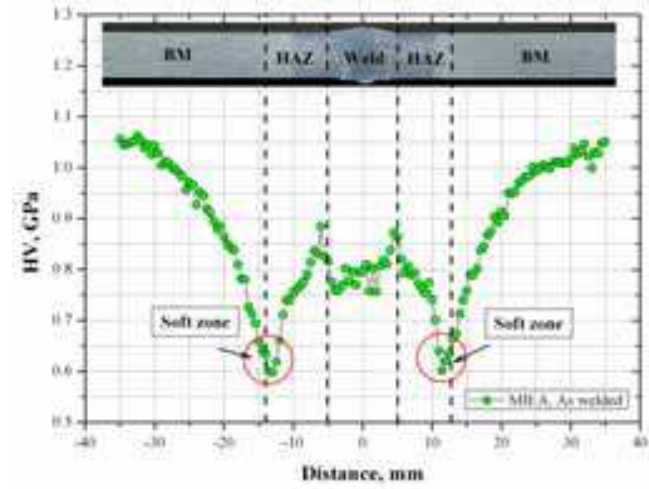

(a)

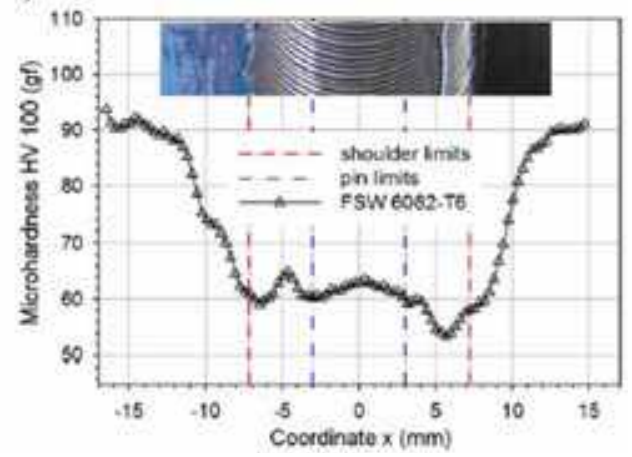

(b)

Fig. 19. Microhardness profile in aluminum alloys welds, a) 6061-T6 alloy welded by MIEA and b) 6082-T6 alloy welded by FSW (Moreira et al., 2007), note that $1 \mathrm{HV}=9.8 \times 10^{-3} \mathrm{GPa}$

Figure 19 presents the Vickers hardness number profile in two different aluminum alloys welds obtained by MIEA and FSW. In both cases a significant difference for the hardness number of the weld material and HAZ with respect to the base material $(\sim 1.05 \mathrm{GPa}$ or 107.1 $\left.\mathrm{HV}_{0.1}\right)$ is observed. Also, at the limit between the HAZ and the base metal, we note the presence of a soft zone which is formed nearly symmetrically in both sides of the welded joints. It should be note that the hardness obtained in this zone represents roughly $57 \%$ of the hardness number of the base material. This seems to indicate that the tensile mechanical properties after welding process will be greatly different. Figure 20 visualizes the location of the soft zone highlighted by the Vickers hardness profile represented in Figure 19a, by means of a hardness mapping. In this figure, the hardness values for each zone of the 
welded joint are well-defined. It is clear that in the soft zone (HAZ) the hardness number range is between 0.55 to $0.7 \mathrm{GPa}$. This soft zone results from the thermodynamic instability of the $\beta^{\prime \prime}$ needle-shaped precipitates (hard and fine precipitates) promoted by the high temperatures reached during a fusion welding process. Indeed the temperatures reached during the welding process are favorable to transform the $\beta^{\prime}$ phase, rod-shaped, according to the transformation diagram for the 6061 alloy.

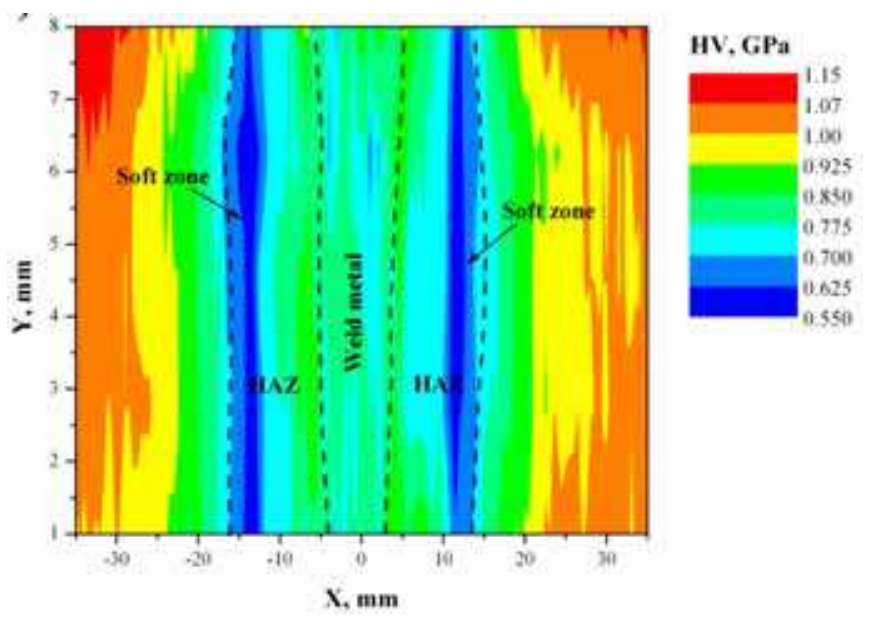

Fig. 20. Vickers hardness mapping over the welded zone

\subsubsection{Tensile properties}

The individual mechanical behaviour of the base metal, weld metal, HAZ and welded samples in as welded condition for 6061-T6 aluminum welds by MIEA is shown in Figure 21 as stress as function of strain graph.

From Figure 21, it can be observed that the experimental results for the base metal are in agreement with nominal values found in the literature for 6061-T6 alloy (American Society for Metals Fatigue and Fracture, 1996). Also, the base metal exhibits the best mechanical properties and well defined proportional limit. The tensile properties of the sample obtained from the HAZ presents a $41 \%$ and a $19 \%$ reduction of the ultimate strength with respect to the base metal and weld metal respectively. The loss of mechanical strength, commonly referred to as over-aging, when welding a 6061-T6 alloy is a fairly well understood phenomenon and it is explained in terms of the precipitation sequence. During welding, however, the base metal adjacent to the fusion line is subjected to a gradient of temperature imposed by the welding thermal cycle. At certain distance from the fusion line, the cooling curve crosses the interval of temperatures between 383 to $250{ }^{\circ} \mathrm{C}$ in which the $\beta$ ' phase, rodshaped, is stable. It is thus the transformation of $\beta$ ' into $\beta$ ' the responsible of the decrease in hardening of the $\alpha$ matrix due to the incoherence of the $\beta^{\prime}$ phase caused by the thermodynamic instability of $\beta$ " in a welding process.

On the other hand, in the case of FSW for 6061-T6, the same effect (over-ageing) is observed, although in this case the welded specimens represents an ultimate strength of $70 \%$ of the base material (Moreira et al., 2007). The conventional stress-strain curves are presented in Figure 22. 


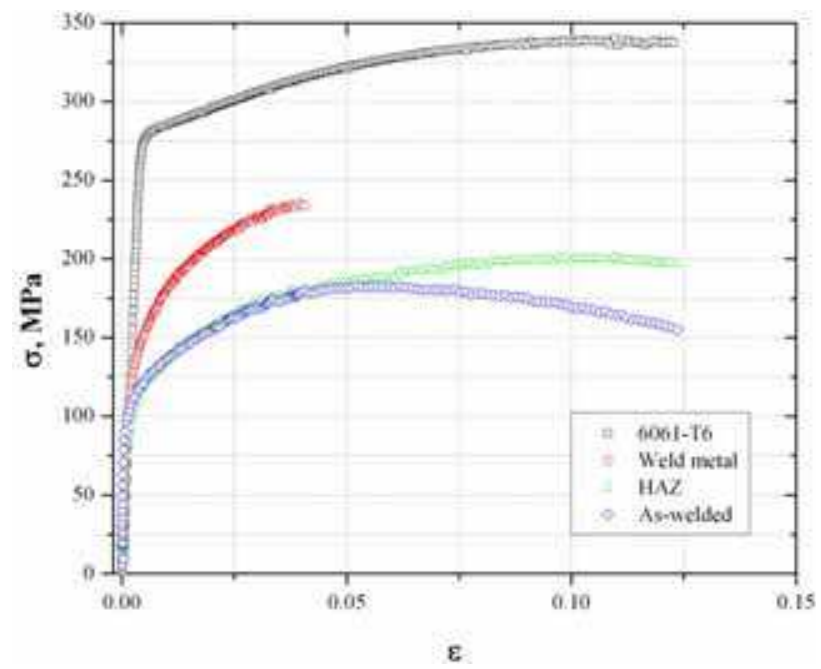

Fig. 21. True stress-strain curves for as-received 6061-T6 plates, weld metal, HAZ, and welds in the as-welded condition

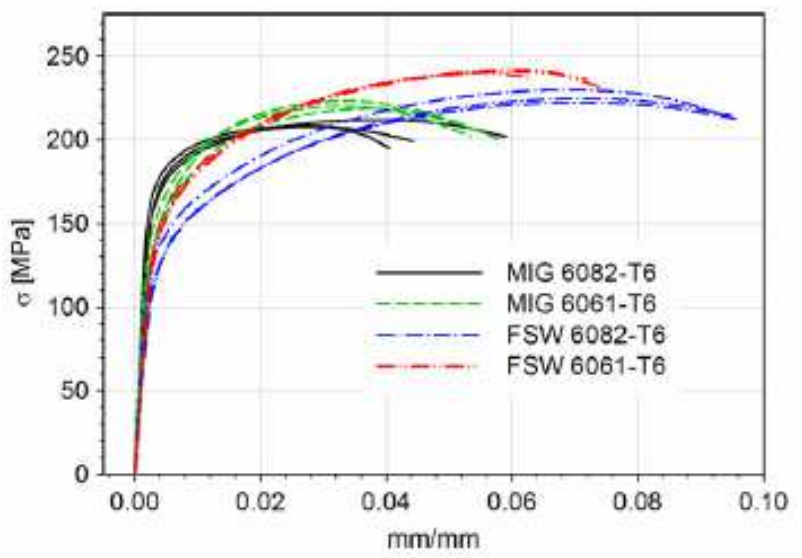

Fig. 22. Tensile tests of MIG and FS welded specimens (Moreira et al., 2007)

\subsubsection{Fatigue crack growth}

Fatigue behavior of aluminum alloys welded by conventional process has been investigated by some authors (Ambriz et al. 2010b; Branza et al., 2009; Seto et al., 2004). In terms of fatigue behavior considering FSW, some interesting studies have been published (Matic \& Domazet, 2005, Chiarelli et al., 1999, James \& Paterson, 1998). This part presents the experimental results in terms of Fatigue Crack Growth (FCG) in the weld metal, heat affected zone and base material of 6061-T6 aluminum alloy welded by MIEA. These results were compared in terms of FCG with those reported previously (Moreira et al., 2008) for FSW of the same alloy. 
Figure 23, presents the crack length as a function of number of cycles for base metal, weld metal and HAZ in 6061-T6 welds by MIEA, for $\Delta P$ equal to 2.5 and $3.0 \mathrm{kN}$. In general, the $a-N$ curves showed in Figure 23 reveal a notable difference in terms of crack length for each material as a function of the number of cycles, nevertheless the small change in $\Delta P$ (Ambriz et al., 2010b).

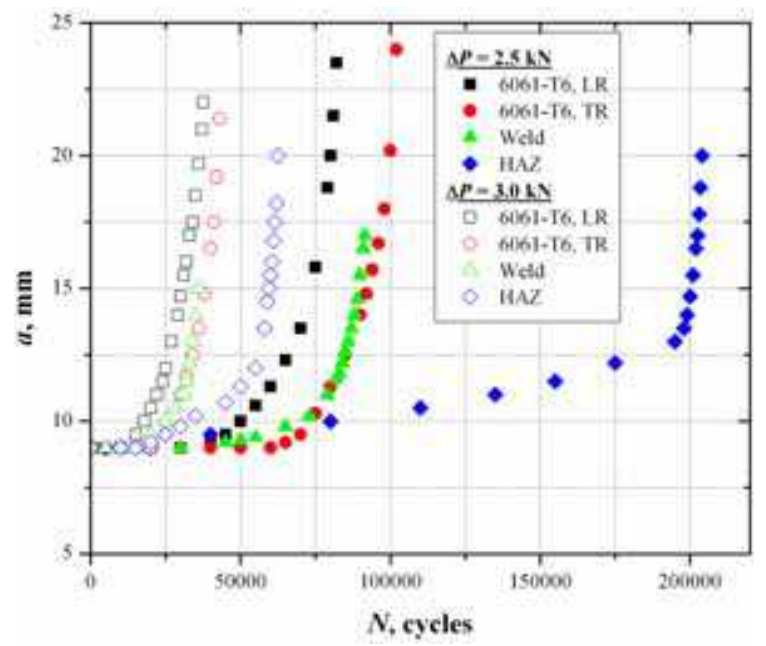

Fig. 23. Graph of crack length as function of number cycles, load ratio, $R=0.1$

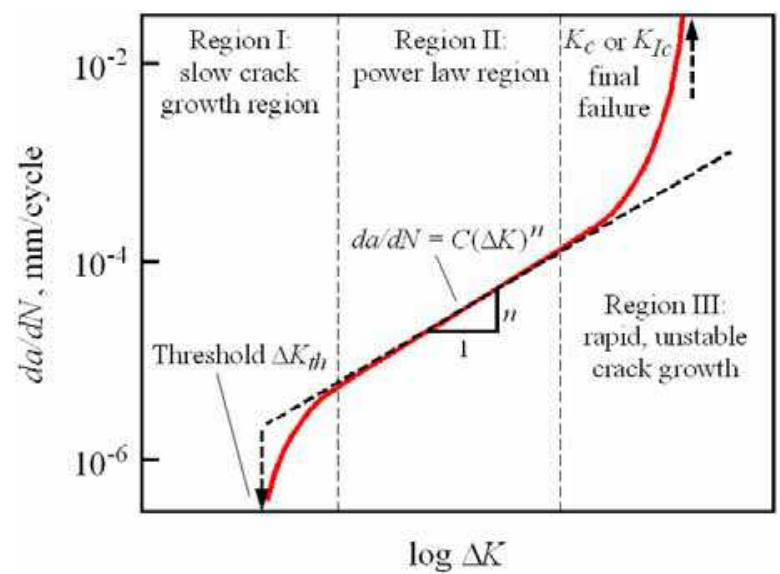

Fig. 24. Fatigue crack growth regimes versus $\Delta K$

Taking into account the power-law region showed in Figure 24, the experimental results for $a$, were plotted in $d a / d N$ versus $\Delta K$ graphs according to Paris law:

$$
\frac{d a}{d N}=C(\Delta K)^{n}
$$


where $C$ and $n$ are constants obtained directly from the fitting curve. Figure 25, presents the FCG data obtained for the base metal, weld metal and HAZ in MIEA, as well as the comparison with FSW data, found in the literature (Moreira et al., 2008). In general terms, the experimental results for MIEA welds adjust very well with equation 3.

a)

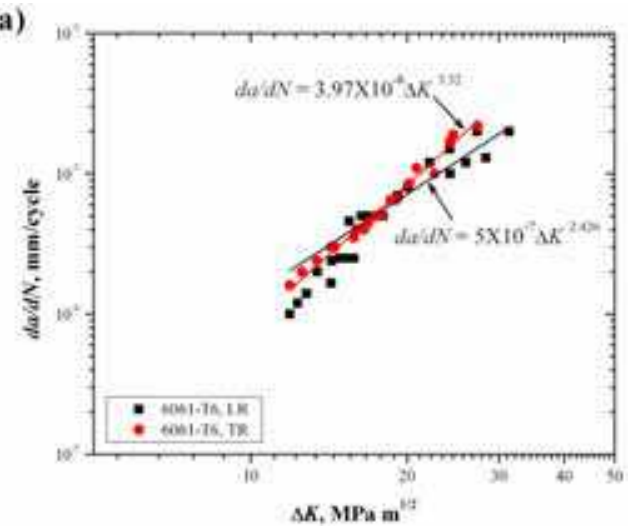

b)

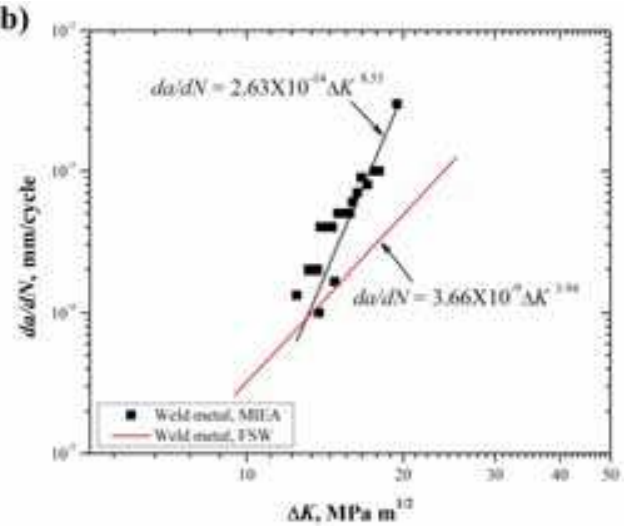

c)

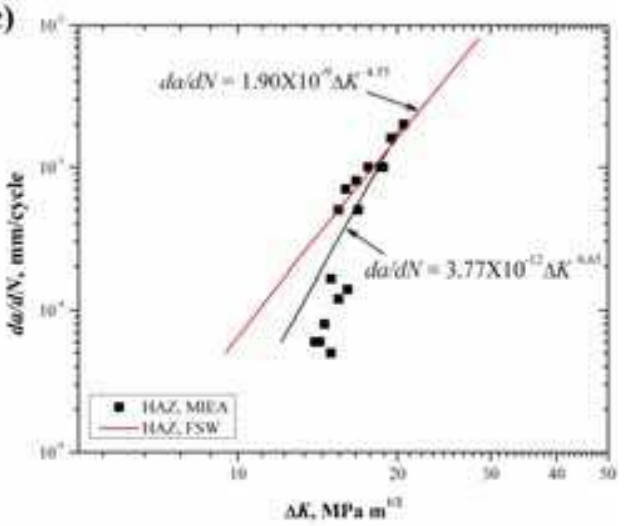

Fig. 25. Fatigue crack growth rate as function of stress intensity factor range

Figure 25a, shows the FCG for base metal in both directions. This graph shows that the microstructure aspect (anisotropy) does not have an important influence in terms of FCG as could be expected, taking into consideration that yield strength in the base metal parallel to rolling direction is higher than transverse direction. However this is not the case for the weld metal and HAZ (Figures 25b-c), in which the crack tends to propagate faster than base metal. Under this scenario, the FCG behavior for base metal (L-T) was taken as a basis to perform a comparative table between the weld metal and HAZ of MIEA and FSW. Table III, presents the crack growth rate, da/dN and the stress intensity factor range $\Delta K$, for base metal, weld metal and HAZ corresponding to a critical crack length in MIEA welds. For comparison effects, values for da/dN in MIEA were taken to compute the $\Delta K$ in FSW. 


\begin{tabular}{|c|c|c|c|c|c|}
\hline & \multirow{2}{*}{$\begin{array}{l}\text { Base } \\
\text { metal }\end{array}$} & \multicolumn{2}{|l|}{ MIEA } & \multicolumn{2}{|l|}{ FSW } \\
\hline & & $\begin{array}{l}\text { Weld } \\
\text { metal }\end{array}$ & HAZ & $\begin{array}{l}\text { Weld } \\
\text { metal }\end{array}$ & HAZ \\
\hline$d a / d N(\mathrm{~mm} /$ cycle $)$ & $1.981 \times 10^{-3}$ & $1.0 \times 10^{-3}$ & $1.413 \times 10^{-3}$ & $1.0 \times 10^{-3}$ & $1.413 \times 10^{-3}$ \\
\hline$\Delta K\left(\mathrm{MPa} \mathrm{m}{ }^{1 / 2}\right)$ & 30.41 & 17.27 & 19.46 & 23.98 & 19.51 \\
\hline$(d a / d N)_{i} /(d a / d N)_{B M}$ & 1.0 & 0.50 & 0.71 & 0.50 & 0.71 \\
\hline$(\Delta K)_{i} /(\Delta K)_{B M}$ & 1.0 & 0.57 & 0.64 & 0.79 & 0.64 \\
\hline
\end{tabular}

$B M=$ base metal, $i$ corresponds to weld metal or HAZ for MIEA or FSW.

Table 3. Comparative table between MIEA and FSW based on a critical crack length

The results presented in table 3 indicate that, there is an important difference in $\Delta K$ for weld metal and HAZ, independently of the welding process. In this way, it should note that $\Delta K$ for weld metal in MIEA represents only $57 \%$ of the base metal, unlike the $\Delta K$ for weld metal in FSW, which reach a 79\% with respect to base metal. This means that FCG rate are higher in MIEA weld metal than FSW, as can be seen in Figure 25b. This behavior is totally related to the joining processes; it means that MIEA is a welding technique based on a fusion welding process that employs a high silicon content filler metal, which produces a self grain refining, but a brittle microstructure in the weld metal (Ambriz et al., 2010c). On the other hand, FSW is a solid-state joining process that does not use a filler metal (Nandan et al., 2008). Thus, chemical composition in weld metal is similar to the base metal and microstructural characteristics related to dynamic recrystalization tends to be better than MIEA.

In contrast, Figure 25c, shows that FCG rate in MIEA and FSW is similar in the HAZ. The stress intensity factor relation was $64 \%$ with respect to base metal. It is noted that thermal effect produced by the microstructural transformation of very fine precipitates needle shape $\beta^{\prime \prime}$, to coarse bar shape $\beta^{\prime}$ precipitates, has a profound impact in the HAZ crack growth rate. It confirms that, independently of the welding process (MIEA and FSW), the crack growth conditions are directly influenced by the temperature within the HAZ, which is normally above of the aging temperature of the alloy, causing a hardening lost and important decrease in mechanical properties.

\section{Conclusion}

Some welding process can be employed to weld aluminum alloys. In this chapter the fundamental characteristics of the most common welding processes have been presented, such as: shielded metal arc welding (SMAW), gas metal arc welding (GMAW), gas tungsten arc welding (GTAW), friction stir welding (FSW), and a new welding technique named modified indirect electric arc (MIEA). Special attention has presented on welding of 6061-T6 aluminum alloy welded by MIEA and FSW. In the case of MIEA welds important microstructural characteristics in terms of morphology and grain size has been observed with respect to those obtained by a multi-pass welding process (GMAW). It means that when 
MIEA is used, the solidification process tends to promote a heterogeneous nucleation, thus an auto-refinement of the grain size is promoted. However, when multi-pass welding process is employed (GMAW) columnar-epitaxial solidification prevails causing an increase in terms of grain size. On the other hand, the grain structure in the fusion zone produced by FSW has the better characteristics in terms of grain size $(\sim 10 \mu \mathrm{m})$.

A few mechanical properties after a welding process of 6061-T6 aluminum alloy have been presented. It is observed that quasi-static mechanical properties decrease in a dramatic manner in MIEA as well as in FSW, this aspect is totally related to the micro-structural transformation in the heat affected zone of very fine needle shape $\beta^{\prime \prime}$ precipitates to coarse bar shape $\beta^{\prime}$ precipitates produced by the thermal effect during the welding process (thermodynamic instability). This micro-structural transformation has been quantified by means of a micro-hardness map from which is possible to observe the soft zone formation where the failures are presented after a monotonic load (tension load).

Fatigue crack growth behaviors in weld metal, HAZ and base metal of 6061-T6 welded joints obtained by MIEA were quantified. It was observed that the worst crack growth conditions are presented in the fusion zone (weld metal), which are related to brittle microstructure characteristics due to abundant presence of eutectic Si. A comparison between weld metal for FSW and the MIEA indicates that fatigue crack growth rate in the MIEA is higher than that in FSW; it means that for a critical crack length, the $\Delta K$ represents a $57 \%$ of the base material, whereas in the case of FSW it reaches a 79\%. In addition, it was observed that the fatigue crack growth rate in the HAZ tends to be similar in both welding processes.

\section{References}

Ambriz, R.R., Barrera, G., \& García, R. (2006). Aluminum 6061-T6 welding by means of the modified indirect electric arc process. Soldagem and Inspecao, Vol. 11, No. 1, pp. $10-$ 17.

Ambriz, R.R., Barrera, G., García, R., \& López V.H. (2008). Microstructure and heat treatment response of 2014-T6 GMAW welds obtained with a novel modified indirect electric arc joint. Soldagem and Inspecao, Vol. 13, No. 3, pp. 255-263.

Ambriz, R.R., Chicot, D., Benseddiq, N., Mesmacque, G. \& de la Torre, S. (2011). Local mechanical properties of the 6061-T6 aluminium weld using micro-traction and instrumented indentation. European eburnal of Mechanics A/Solids, Vol. 30, pp. 307315.

Ambriz, R.R., Mesmacque, G., Ruiz, A., Amrouche, A., López, V.H. (2010). Effect of the welding profile generated by the modified indirect electric arc technique on the fatigue behavior of 6061-T6 aluminum alloy. Materials Science and Engineering $A$, Vol. 527, pp. 2057-2064.

Ambriz, R.R., Barrera, G., García, R. \& López, V.H. (2010). The microstructure and mechanical strength of Al-6061-T6 GMA welds obtained with the modified indirect electric arc joint. Materials and Design, Vol. 31, No. 6, pp. 2978-2986.

Ambriz, R.R., Mesmacque, G., Ruiz, A., Amrouche, A., López, V.H. \& Benseddiq, N. (2010). Fatigue crack growth under a constant amplitude loading of Al-6061-T6 welds obtained by modified indirect electric arc technique. Science and Technology of Welding and ebining, Vol. 15, No. 6, pp. 514-521. 
Branza, T., Deschaux-Beaume, F., Velay, V. \& Lours, P. (2009). A microstructural and lowcycle fatigue investigation of weld-repaired heat-resistant cast steels. dburnal of Materials Processing Technology, Vol. 209, No. 2, pp. 944-953.

Chiarelli, M., Lanciotti, A. \& Sacchi, M. (1999). Fatigue resistance of MAG welded steel elements. International burnal of Fatigue, Vol. 21, No. 10, pp. 1099-1110.

Davies, G.J. \& Garland J.G. (1975). Solidification structures and properties of fusion welds. International Metals Review, Vol. 20, pp. 83-106.

Dawes, C.J. \& Thomas, W.M. (1996). Friction stir process welds aluminum alloys. Welding eburnal, Vol. 75, 3, pp. 41-45.

Dutta, I. \& Allen, S.M. (1991). Calorimetric study of precipitation in commercial Al alloys. cburnal of Materials Science Letters, Vol. 10, pp. 323-326.

Easterling, K. (1992). Introduction to the Physical Metallurgy of Welding (Second Edition), Butterworth Heinemann, ISBN 0750603941, Oxford.

Grong, O. (1997). Metallurgical Modeling of Welding, (Second Edition), The Institute of Materials, ISBN 1861250363, London.

James, M.N. \& Paterson, A.E. (1997). Fatigue performance of 6261-T6 aluminium alloy constant and variable amplitude loading of parent plate and welded specimens. International eburnal of Fatigue, Vol. 19, No. 93, pp. 109-118.

Kou, S. (2003). Welding Metallurgy (Second Edition), John Wiley and Sons, ISBN 0-471-434914, United States of America.

Li, Y., Murr, L.E. \& McClure, J.C. (1999). Flow visualization and residual microstructures associated with the friction-stir welding of 2024 aluminum to 6061 aluminum. Materials Science and Engineering A, Vol. 271, pp. 213-223.

Lin, D.C., Wang, G.X. \& Srivatsan T.S. (2003). A mechanism for the formation of equiaxed grains in welds of aluminum-lithium alloy 2090. Materials Science and Engineering A, Vol. 351, pp. 304-309.

Liu, G., Murr, L.E., Niou, C.S., McClure, J.C. \& Vega, F.R. (1997). Microstructural aspects of the friction-stir welding of 6061-T6 aluminum. Scripta Materialia, Vol. 37, No. 3, pp. 355-361.

Mahoney, M.W., Rhodes, C.G., Flintoff, J.G., Spurling, R.A. \& Bingel, W.H. (1998). Properties of friction-stir-welded 7075 T651 aluminum. Metallurgical Materials Transactions, Vol. 29, pp. 1955.

Matic, T. \& Domazet, Z., (2005). Determination of structural stress for fatigue analysis of welded aluminium components subjected to bending. Fatigue and Fracture Engineering Materials and Structures, Vol.28, No. 9, pp. 835-844.

Mishra, R.S. \& Ma, Z.Y. (2005). Friction stir welding and processing. Materials Science and Enginnering $R$, Vol. 50, pp. 1-78.

Moreira, P.M.G.P, de Jesus, A.M.P., Ribeiro, A.S., \& Castro, P.M.S.T. (2008). Fatigue crack growth in friction stir welds of 6082-T6 and 6061-T6 aluminium alloys: as a comparison. Theoretical and Applied Fracture Mechanics, Vol. 50, pp. 81-91.

Moreira, P.M.G.P, Figueiredo, de M.A.V. \& Castro, P.M.S.T. (2007). Fatigue behaviour of FSW and MIG weldments for two aluminium alloys. Theoretical and Applied Fracture Mechanics, Vol. 48, pp. 169-177.

Myhr, O.R., Grong, O., Fjaer, H.G., \& Marioara, C.D. (2004). Modelling of the microstructure and strength evolution in Al-Mg-Si alloys during multistage thermal processing. Acta Materialia, Vol. 52, pp. 4997-5008. 
Nandan, R., DebRoy, T. \& Bhadeshia H.K.D.H. (2008). Recent advances in friction-stir welding-process, weldment structure and properties. Progress in Materials Science, Vol. 53, pp. 980-1023.

Ram, G.D.J, Mitra, T.K., Raju, M.K. \& Sundaresan, S. (2000). Use of inoculants to refine weld solidification structure and improve weldability in type 2090 Al-Li alloy. Materials Science and Engineering A, Vol. 276, pp. 48-57.

Rao, K.P., Ramanaiah, N. \& Viswanathan, N. (2008). Partially melted zone cracking in AA6061 welds. Materials Design, Vol. 29, pp 179-186.

Rhodes, C.G., Mahoney, M.W., Bingel, W.H., Spurling, R.A. \& Bampton C.C. (1997). Effects of friction stir welding on microstructure of 7075 aluminum. Scripta Materialia, Vol. 36, No. 1, pp. 69-75.

Sato, Y., Urata, M. \& Kokawa H. (2002). Parameters controlling microstructure and hardness during friction-stir welding of precipitation-hardenable aluminum alloy 6063 . Metallurgical Materials Transactions A, Vol. 33, No. 3, pp. 625-635.

Sato, Y.S. Kokawa, H., Enmoto, M. \& Jogan, S. (1999). Precipitation sequence in friction stir weld of 6063 aluminum during aging. Metallurgical and Materials Transactions A, Vol. 30, No. 12, pp. 3125-3130.

Seto, A., Yoshida, Y. \& Galtier, A. (2004). Fatigue properties of arc-welded lap joints with weld start and end points. Fatigue and Fracture Engineering Materials and Structures, Vol. 22, No. 12, pp. 1147-115.

Thomas, W.M. \& Dolby R.E. (2003). Friction Stir Welding Developments, Proceedings of the Sixth International Trends in Welding Research, Materials Park, OH, USA.

Thomas, W.M., Nicholas, E.D., Needham, J.C., Murch M.G., Temple-Smith P. \& Dawes C.J. (1991). Friction Stir Butt Welding. International Patent Application No. PCT/GB92/02203. 


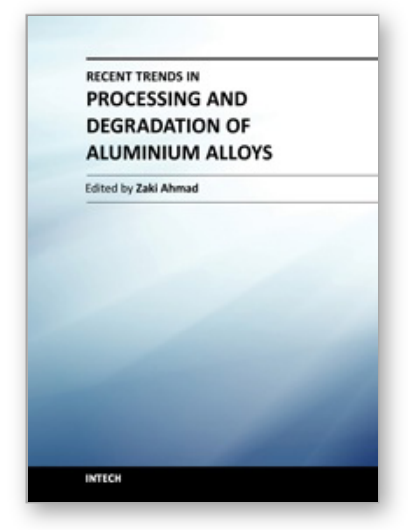

\section{Recent Trends in Processing and Degradation of Aluminium Alloys \\ Edited by Prof. Zaki Ahmad}

ISBN 978-953-307-734-5

Hard cover, 516 pages

Publisher InTech

Published online 21, November, 2011

Published in print edition November, 2011

In the recent decade a quantum leap has been made in production of aluminum alloys and new techniques of casting, forming, welding and surface modification have been evolved to improve the structural integrity of aluminum alloys. This book covers the essential need for the industrial and academic communities for update information. It would also be useful for entrepreneurs technocrats and all those interested in the production and the application of aluminum alloys and strategic structures. It would also help the instructors at senior and graduate level to support their text.

\section{How to reference}

In order to correctly reference this scholarly work, feel free to copy and paste the following:

R.R. Ambriz and V. Mayagoitia (2011). Welding of Aluminum Alloys, Recent Trends in Processing and Degradation of Aluminium Alloys, Prof. Zaki Ahmad (Ed.), ISBN: 978-953-307-734-5, InTech, Available from:

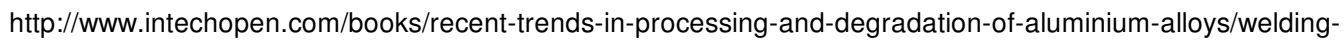
of-aluminum-alloys

\section{INTECH}

open science | open minds

\section{InTech Europe}

University Campus STeP Ri

Slavka Krautzeka 83/A

51000 Rijeka, Croatia

Phone: +385 (51) 770447

Fax: +385 (51) 686166

www.intechopen.com

\section{InTech China}

Unit 405, Office Block, Hotel Equatorial Shanghai

No.65, Yan An Road (West), Shanghai, 200040, China

中国上海市延安西路65号上海国际贵都大饭店办公楼 405 单元

Phone: +86-21-62489820

Fax: +86-21-62489821 
(C) 2011 The Author(s). Licensee IntechOpen. This is an open access article distributed under the terms of the Creative Commons Attribution 3.0 License, which permits unrestricted use, distribution, and reproduction in any medium, provided the original work is properly cited. 